\title{
The role of the educator in a social software environment: A conceptualisation and research agenda
}

Higher and further education institutions are increasingly using social software tools to support teaching and learning. A growing body of research investigates the diversity of tools and their range of contributions. However, little research has focused on investigating the role of the educator in the context of a social software initiative, even though the educator is critical for the introduction and successful use of social software in a course environment. Hence, we argue that research on social software should place greater emphasis on the educators, as their roles and activities (such as selecting the tools, developing the tasks and facilitating the student interactions on these tools) are instrumental to most aspects of a social software initiative. To this end, we have developed an agenda for future research on the role of the educator. Drawing on role theory, both as the basis for a systematic conceptualization of the educator role and as a guiding framework, we have developed a series of concrete research questions that address core issues associated with the educator roles in a social software context and provide recommendations for further investigations. By developing a research agenda we hope to stimulate research that creates a better understanding of the educator's situation and develops guidelines to help educators carry out their social software initiatives. Considering the significant role an educator plays in the initiation and conduct of a social software initiative, our research agenda ultimately seeks to contribute to the adoption and efficient use of social software in the educational domain.

\section{Introduction}

Social software tool such as wikis, blogs, and social networking sites are increasingly used in the higher education domain and have received widespread attention. A number of reports in the last years have shown how social software tools positively contribute to a wide range of teaching and learning practices (Kieslinger, 2009). For example, students use blogs as online reflective diaries to describe their own learning experiences as well as to comment on learning logs kept by other course participants (Du \& Wagner, 2007), or student teams or entire courses use a wiki to collaboratively create and continuously refine course content (Trentin, 2009). It is widely accepted that social software's ability to support conversational interaction and social feedback among students and to enable social networks and relationships offers significant potential for enhancing teaching and learning practices (McLoughlin \& Lee, 2007).

Introducing social software into a course environment also has considerable implications for the role of the educator. Educators in a social software initiative not only take on the role of facilitators, who (as in traditional learning contexts) initiate and guide the knowledge construction process among students (Choy \& $\mathrm{Ng}$, 2007), but also take up new roles, such as acting as technologists who select, set up and maintain the software tools for their students (McGee \& Diaz, 2007). Other accounts describe how educators act as course designers by carefully selecting and matching the pedagogy appropriate for the particular tools used (JISC, 2009), or act as online role models who demonstrate their students appropriate forms of interaction in these environments (Hurlburt, 2008). 
A considerable amount of research attention is put on the different ways social software can be used and the value these initiatives can add to teaching and learning, but it is the individual educator carrying out different roles and activities who enables these initiatives. In a large number of cases, social software initiatives are not conducted by dedicated support teams but by individual educators who carefully integrate the tools into the course environment and provide the necessary student support (Minocha, 2009b). The diverse roles of the educators are therefore crucial for the efficient and sustainable use of these tools in a course environment.

To investigate the role of the educator in a social software initiative requires a careful conceptualization of the role phenomenon. Educators traditionally perform a considerable array of teaching, research and administrative roles (eg course development, lecturing, marking, serving on committees, and acting as journal referees or editors). In comparison to corporate environments, job roles in the higher education domain often lack clear definitions and boundaries (Taylor, 1999). The principles of academic freedom and self-administration allow educators to select and perform different roles with a high level of independence. This independence, while allowing educators to integrate their expertise and creativity into their work (helping to advance teaching practices and research agendas), can create considerable uncertainties among educators and overwhelm them with the range and diversity of tasks (Winter \& Sarros, 2002). Minocha (2009b) describes a range of these uncertainties educators may experience when being involved in a social software initiative: uncertainties about the extent to which they should monitor student interaction; uncertainties about blurring the boundaries between personal and academic life when interacting with students on social networking tools such as Facebook; uncertainties about how to deal with inappropriate content (eg pictures, text), especially when using social software tools which are openly accessible, such as the picturesharing site Flickr.com. Educators can not easily control the content which students create or the content students are exposed to, and there is considerable uncertainty about the legal implications such inappropriate activities could create for the University.

Considering the uncertainties educators experience by being part of a social software initiative, it is necessary to develop a research agenda that focuses on the educators in these environments, rather than only focusing on the tools and their educational value. In this paper, we seek to develop a research agenda to investigate the changing role of the educator in a social software environment. Drawing on role theory, both as the basis for a systematic conceptualization of the educator role and as a guiding framework, we develop a series of concrete research questions that address core issues associated with the educator roles in a social software context in order to stimulate and guide future research.

The paper is structured as follows. We first define social software and describe the predominant ways in which individual social software tools are used to facilitate teaching and learning in the higher and further education domain. Following this, we outline the core concepts of role theory and its predominant research approaches. We show how the theoretical propositions and research perspectives of role theory apply to the educator in a social software initiative and how they lead to several salient research questions. The paper concludes with recommendations for further investigation of the role of the educator and we provide practical recommendations for educators carrying out social software initiatives. 


\section{Social Software}

The term social software refers to a variety of tools for online (social) interaction, including blogs, forums and social networking sites (for a wider list and more detailed descriptions of the individual tools see Table 1). Following Parameswaran and Whinston (2007), we define social software as a category of "applications and services that facilitate collective action and social interaction online with rich exchange of multimedia information and evolution of aggregate knowledge" (p. 762). A distinguishing attribute of social software is that its content is user generated; hence, this content is highly dynamic with frequent, often unpredictable changes. As an example, a discussion thread in a forum is created through user interaction and the course of the discussion often takes an unpredictable direction. Further, the mechanisms for monitoring and guarding content quality are often distributed, with fellow users reviewing each others' contributions. A good example is the wiki-based quality control mechanism where every user is able to refine and correct contributions made by others. From a technical standpoint, social software applications are mostly lightweight tools which are accessed through a Web browser, and are thus highly portable, and are platform independent.

Despite their similarities, different social software tools have unique features which create distinct contributions for teaching and learning. Four core contributions of social software to the educational domain have been identified by McLoughlin and Lee (2007): 1) build connectivity and social rapport: students build social connections and develop supportive relationships (eg social networking tools like Facebook); 2) facilitate collaborative information discovery and sharing: students share their learning resources with each other (eg social bookmarking tools); 3 ) support content creation: students collaboratively create and share content with each other (eg wiki); and 4) knowledge and information aggregation and content modification: students easily syndicate and aggregate diverse sources of content (eg in a blog). Details on how social software tools are commonly used in higher education teaching and learning are provided in Table 1.

Due to their diverse contributions social software are used in a wide range of course environments. Social software tools are used to augment the traditional face to face learning experience as well as to deliver or support distance learning courses. For example, students in regular lecture-based courses are provided with blogs or wikis so that they can engage in collaborative knowledge creation outside the lecture or seminar (Du \& Wagner, 2007). On the other hand, blogs or discussion boards are used in distance or online learning courses as a platform for facilitating peer support among students and to provide a successful avenue for overcoming the feeling of isolation among distance students (eg Dickey, 2004; Kerawalla, Minocha, Kirkup, \& Conole, 2009). While the particular contributions of social software tools might differ between different course environments there is no inherent limit regarding the course context or subject areas where social software is (or can be) used.

$=====$ Table 1 here=====

With the literature focusing on describing the diversity of social software tools and learning scenarios, only few studies have addressed the role of the educator in these environments. 
Notably, studies on the educational use of wikis describe how educators and students become cocreators of learning content or partners in learning (Frydenberg, 2008), and it is recommended that educators in these environments give up their authority and instead focus on the monitoring of student interaction (Jones \& Gelb, 2009); studies on the educational use of blogs highlight how educators should act as online role models (Hurlburt, 2008). Research on the educational use of discussion boards has demonstrated more focused interest in the educators' roles and activities, primarily owing to the relatively long history of using discussion boards in learning management systems. Although students are capable of taking responsibility for the development of online discussions without significant educator intervention and participation (Kay, 2006), several studies and guidelines outline how educators should organize discussion forums, monitor student interactions, and, if necessary, refocus discussions by posting intermittent feedback (Dennen, 2005; Roberson \& Klotz, 2002). Clearly, with the exception of studies on discussion boards, most research on social software focuses on tools and learning scenarios, without explicitly considering the different roles an educator performs or discussing how the diverse educator roles relate to goals and objectives of the social software initiative.

While the social software research so far has put little emphasis on the role of the educator, this topic has received a lot more attention in the wider online learning literature. Several explicit frameworks outline the considerable array of roles educators perform in online environments. Berge's (1995) frequently used framework highlights how educators in an online learning context perform a range of pedagogical roles, managerial roles, social roles and technical roles. Hence, an educator undertakes various activities to facilitate the learning processes; to organize and co-ordinate the student interaction; to promote a community feeling among students; and to oversee the technical aspects of the online environment. Further frameworks describing the diversity of educator roles are reviewed by De Laat, Lally, Lipponen and Simons (2007). While most of these frameworks interpret the online educator roles as categories of activities, Heuer and King (2004) expand this notion by focusing on the expectations others have towards the educator, rather than on actual activities. Hence, their research, identifying the online educator role from the student perspective, conceptualizes the educator as a planner, model, coach, facilitator and communicator.

The literature provides us with a range of descriptions on the different roles educators perform in a (general) online learning environment but it is not clear to which extent these roles apply to educators in a social software context. Although social software tools to some extent constitute an online environment, their particular characteristics create a distinct context for educators. Integrating these tools into a learning context provides students with a high level of independence for creating, consuming and sharing of content (Greenhow, Robelia, \& Hughes, 2009). While in traditional online-learning environments the learning material is largely provided by the educator, social software tools position the students as a knowledge consumer and a knowledge provider, thereby challenging the educators' established roles. The fact that social software tools are often publicly accessible and not owned and operated by the learning institutions constitutes an important point of distinction with traditional university-operated online learning environments. The opportunities for controlling public social software environments and the respective student interaction are clearly limited, requiring the educator to perform different activities to guide the learning activities. Also, while online teaching is based on a distance learning paradigm, social software is often used not to replace, but to supplement 
face to face interaction, requiring the educators to perform both online and off-line roles. Further, social software initiatives are often carried out by individual entrepreneurial educators (Minocha, 2009b), and are not the result of a strategic course development (as online learning courses generally are) which is likely to require the educator to carry out additional roles.

Social software research to date has made considerable progress in understanding how social software can add to teaching and learning practice. However, studies which specifically focus on the role of the educator in social software environments are still very scarce. With the individual educator being the driving force behind the majority of social software initiatives, understanding his or her roles and activities in these environments is critical. In the remainder of this paper we focus on conceptualizing the role of the educator in a social software initiative and mapping out a research agenda for future investigations. In the next section we illustrate role theory as a viable theoretical underpinning to understand and systematically investigate the educator role.

\section{Role theory and its underlying concepts}

Role theory summarizes a body of sociological research which focuses on identifying the circumstances and mechanisms under which individuals perform particular social or organizational 'roles', such as the role of a friend or the role of a supervisor. Biddle (1986) defines role theory as "a triad of concepts: patterned and characteristic social behaviours, parts or identities that are assumed by social participants, and scripts or expectations for behaviour" (p. 68). The behaviours of an individual, his or her social position, and the expectations towards the individual form the core constructs of role theory and conceptualize the different dimensions of the role phenomenon.

Role behaviour, social position, and role expectations are not independent constructs, and their relationships are subject to intensive examination. Role behaviour is often at the centre of the investigation and studies have focused on how social position and expectations of others influence the behaviour of an individual. Especially the impact of one's social position or social status has received considerable attention, with studies confirming how aspects of gender, ethnicity, sexual orientation, and social class shape individual behaviour (Lopata, 1995). Further, studies demonstrate the importance of others' expectations in shaping a person's behaviour in a workplace context (Mantere, 2008). In addition to investigating the relationship between behaviour, social position, and expectations, role theory also focuses on how these different role aspects relate to the context in which an individual is situated. Especially work-based studies have shown how the organizational context shapes both the expectations individuals have towards a role (Dierdorff \& Morgeson, 2007) and the actual role behaviour of an individual (Wickham \& Parker, 2007).

Conceptualizing a role as a triad of behaviours, positions, and expectations opens up opportunities to understand a range of issues people experience as part of their social or work life. Within role theory, the mismatch between different role aspects is considered a major source for stress and conflict (Sieber, 1974). A mismatch between a superior's role expectations and one's own actual role behaviour is a source of role conflict, often leading to dispute. Role overload describes a situation where a person is faced with a set of roles that are too complex and demanding, leading to stress and anxieties. Role ambiguity, describing a situation where the expectations and descriptions for adequate role performance for a given position are unclear 
(Davis, 1997) is equally considered as source of anxiety in workplace research. The concepts and frameworks of role theory not only explain individual behaviour, but also allow for the analysis and explanation of several social or workplace related issues.

To summarise, role theory, with its established frameworks and research perspectives, offers a sound theoretical basis for understanding behaviours and activities in a social and workplace context. By conceptualizing the role as a multi-dimensional phenomenon, role theory helps to systematically analyse and explain patterns of behaviour and sources of conflict. Hence, we will use the frameworks and research perspectives of role theory to conceptualize the role of the educator in a social software environment and develop an agenda for future research.

\section{Conceptualizing the role of the educator and developing a research agenda}

We will now conceptualize the role of the educator by following the established frameworks and research perspectives of role theory. Our conceptualisation commences by first applying Biddle's (1986) notion of a role as behaviour, social position, and expectation to the educator in a social software initiative. The discussion of each of these dimensions raises a number of research questions that should be answered to gain a deeper understanding of the educator role. We will then focus on the influence of the external environment on the educator role and develop research questions that take into account the nature of the technology and the learning objectives. Our conceptual framework is provided as Figure 1.

Discussions on the role of the educator in the social software literature are largely focused on the behavioural aspects of the role concept. Studies describe how educators in these environments monitor student interactions (Jones \& Gelb, 2009), or act as online role models (Hurlburt, 2008). However, the descriptions of the behavioural changes are mostly limited to illustrating a few, selected behaviours without consideration of the wide range of role behaviours an educator carries out in a social software initiative. This focus on the behavioural aspects is equally predominant in the online learning literature where the role of the educator is conceptualized through specific pedagogical, managerial and technical behaviours (eg Berge, 1995). While the existing online learning frameworks show the diversity of role behaviours within an educator role, there are additional roles that an educator may perform in a social software environment. In order to investigate the role of the educator in a social software initiative it is critical to identify the range of behaviours educators perform:

Research Question 1: What are the behaviours educators perform as part of a social software initiative?

\section{The social position of the educator}

The social position is another important facet which is required for the systematic description of the role of the educator. Formal aspects such as rank, job title, and committee memberships, but also informal aspects such as reputation and relationships with other stakeholders are important characteristics that define the social position of an educator. As social software initiatives are 
commonly initiated and carried out by individual educators (JISC, 2009), this involvement is not likely to be part of their formal job-descriptions. Consequently, in the case of a social software initiative, the reputation and relationships of the individual educator are of primary importance. An educator's reputation and relationships are likely to provide access to expert advice, institutional support, and possibly even funding for the social software initiative. For an educator, the social position and status may facilitate conducting the social software initiative, as they may obtain the necessary support for activities others may have to carry out themselves. Hence, considering the effects of the social position on the educator's behaviours and activities can give important insights into the reasons for success and failure of social software initiatives.

Research question 2.1: How does the social position of the educator influence role behaviour in a social software initiative?

The relationship between social position and role behaviour is an important area of investigation as any mismatch between these two facets of an educator role may result in some form of role issues. In the educational context the risk of such a mismatch lies in the extent to which additional roles are not formally recognised as part of the educators pedagogic and administrative responsibilities. Not having these additional roles formalized in job descriptions may result in a form of role overload in which the capacities of the educator are exceeded. Such scenarios give rise to the following research question.

Research question 2.2: What are the effects of a mismatch between the formally recognised roles and actual role behaviour of an educator?

\section{The expectations towards the role of the educator}

The third major concept of role theory is related to role expectations; in the context of social software initiatives, this aspect is of particular interest. To the best of our knowledge, there has been no research in the systematic analysis of role expectations. However, there are studies that suggest, as anecdotal evidence, expectations students have towards the educator in a social software context. Choy and $\mathrm{Ng}$ (2007), for example, highlight how students expect the educator to actively use the wiki environment to raise important questions and initiate discussions. As the students are the main stakeholders of the educator's activity, identifying their expectations towards the role of the educator in these environments helps in understanding the network of expectations in which an educator is situated.

Research question 3.1: What expectations do students have towards the role of the educator in a social software initiative?

Identifying the student expectations does not just provide us with an understanding of another facet of the educator role but is also likely to help us understand the mechanisms through which educators adapt their role. Role theory has clearly identified how others' expectations influence the range of roles a person performs (Biddle, 1986). With the students being the main stakeholders of the social software initiative, their expectations are likely to have a strong influence on the behaviour and activities of the educator. Investigating how students' 
expectations influence the educators' role behaviour would clarify the range of educators behaviours.

Research question 3.2: How do the expectations of students influence the role behaviour of the educator in a social software initiative?

Students may have used social software before entering the higher education system. Therefore, they may have formed expectations about specific communication practices that have developed within these social software environments. Consequently, educators often find themselves overwhelmed by the quantity of student communication and the rise in their expectations for immediate response (Anderson, 2008). Following role theory, the mismatch between role expectations and role behaviour constitutes a major source of stress and tension among those involved. Considering the potential implications that are created by the discrepancy between students' expectations and educators' behaviour, a dedicated investigation of the impact of this discrepancy is warranted.

Research question 3.3: What are the effects of a mismatch between student's role expectations and the educator's role behaviour?

The relationship between social software initiative and educator role

Role theory, as we have seen, enables a conceptualization of the different facets of the educator role and their internal relationship. Role theory also emphasises that the role of an educator should be investigated in a particular context. A social software initiative is a multi-dimensional phenomenon which can be characterized by its pedagogical aims, the technologies employed and the stakeholders involved. To conceptualize the impact on the role of the educator we need to focus on contextual aspects of the social software initiative: the choice of social software tools and the particular teaching and learning objectives.

A considerable variety of social software tools with distinct affordances are used to support teaching and learning. For example, blogs allow people to create content individually and communicate with others via commenting; in contrast, wikis enable people to create content collaboratively as well as engage in discussions about the content; social bookmarking sites enable the aggregation of learning resources; image-sharing sites enable the display of student work. Although it can be expected that an educator in a blogging environment might be more focused on providing social support than in a wiki environment, the social software literature so far has not investigated how the different tool characteristics influence the role behaviour of the educator.

Research question 4.1: How do the characteristics of the social software tool influence the role behaviour of the educator?

The different social software tools are not only characterized by their affordances, but also the way these tools are used and associated with on the Web. Whereas tools such as discussion boards or wikis are largely used in the context of thoughtful deliberation, students use social networking sites and micro-blogging applications largely for socialization and networking. 
Hence, students' prior experiences in using these tools are likely to create distinct expectations regarding the range of activities educators should engage in when using these tools.

Research question 4.2: How do students' prior experiences with particular tools influence role expectations?

The influence of the technology is further complicated by the fact that students are used to interacting with educators in a face-to-face environment. Students therefore develop particular expectations towards the role of the educator based on the traditional teaching and learning mode. However, these face-to-face expectations are likely to be different from the expectations in the context of a social software environment. Consolidating these different expectations is a particular challenge for the students as well as the educator.

Research question 4.3: What are the effects of a discrepancy between the expectations students have towards the educators in a social software initiative and in a face-to-face environment?

The impact of the implementation objectives on the role of the educator

The objectives for integrating a particular social software tool is also likely to influence the range of roles an educator performs. McLoughlin and Lee's (2007) catalog of contributions of social software indicates the diversity of objectives for implementing particular tools (esp. to build social connectivity, to facilitate collaborative information discovery, to support content creation, to encourage knowledge aggregation). An educator who introduces a blog to create social connectivity among students is likely to perform different and much more supportive roles within these blogs than an educator who ask students to use a blog as project-diaries. The extent to which an educator performs social and motivational roles might be considerably different depending on the objectives of adopting social software within a course or activity. Therefore:

Research question 5.1:

How do the teaching and learning objectives of the social software initiative influence the roles of the educator?

\section{Discussion}

There is little doubt about the value of incorporating social software into teaching and learning practice. Social software tools can provide significant support to both traditional teaching and distance education programs by facilitating interaction, collaboration, and the formation of social networks among students (eg McLoughlin \& Lee, 2007; Minocha, 2009a). Although the tool characteristics offer tremendous opportunities, these are hardly brought to fruition without educators who embed the tools in a larger learning context, who assure the suitability of the tools, and who monitor the students proper engagement with the tools. Unlike other educational innovations such as the introduction of course management software (or virtual learning environments), or the creation of institutionally driven online learning courses, social software initiatives are largely created by individual entrepreneurial educators who seek to use the potential of these tools to enhance teaching in the courses they are responsible for (JISC, 2009). 
Although educators initiate and drive a social software initiative, their roles within such an initiative are under-conceptualized. The application of role theory has enabled us to conceptualize the diverse dimensions of an educator's role. The conceptualization has led to the development of a research agenda and a range of research questions that are salient for the future investigation of the educator's role in a social software initiative. The conceptualisation and generation of the research agenda are relevant for educational researchers but also show the range of practical implications for educators involved in social software initiatives. Helping educators to disentangle their complex roles as behaviors, social positions, and expectations not only provides an awareness of their situation and the constrains in which they operate but also helps to explain some of the problems they encounter. Several of the difficulties educators experience can be identified as symptoms of role overload, role ambiguity or role conflict, which we now elaborate.

One of the core problems educators face during the introduction of social software tools is related to the concept of role overload: as social software initiatives are largely initiated by educators in addition to existing course commitments (Minocha, 2009b), these initiatives carry a high risk of over-exerting the resources available to the individual educator (McGee \& Diaz, 2007). Unfortunately, the necessary institutional support, for example, providing technical and administrative assistance to the educator, is often not available. Adding to the risks of role overload is the fact that the educational community to date has very little experience in the efficient use of these tools. For the majority of these tools a high level of role ambiguity exists, as little research and guidance is available on the roles and activities an educator should perform to achieve the expected benefits. In addition to formal research, one way to address this uncertainty is through sharing of the experiences by those educators who have already used these tools in a course environment. Fortunately, those educators are often very willing to share their experiences, as can be seen in the growing number of reports and blog-entries (for example, see http://scienceoftheinvisible.blogspot.com), although, the focus of these publications to date is largely focused on the tool use and less on the associated educator roles.

Another important issue is related to the expectations of students in these environments and the potential for conflict between student expectations and the actual educator behaviour, particularly with regards to the immediacy of educator responses and their level of engagement (Anderson \& Elloumi, 2008). There is no doubt that educators will need to adjust their behaviour to the particular circumstances of these social software environments; however, in order to avoid such role conflict and misunderstandings it would be advisable to educate the students about what kind of interventions they can realistically expect from the educator (Anderson \& Elloumi, 2008). While some issues, such as the lack of institutional support can not easily be solved by the individual educator, other issues, such as the unrealistic expectations from students can be addressed. Educators who are involved in a social software initiative are advised to take these and other role issues into account and actively focus on addressing them for the success and sustainability of the initiatives.

The role issues that we have highlighted in this paper are significant as they can result in the dissatisfaction of an individual educator (eg, role overload) and can inhibit the adoption of social software into the teaching and learning contexts. By developing a research agenda for the future investigation of the role of the educator, we also hope to contribute to raising the awareness of 
managers and policy makers about the diverse roles that an educator performs as part of a social software initiative, the support an educator requires, and the consequences of the institutional support on the transferability and sustainability of the social software initiatives.

\section{Conclusion}

Our present work contributes to the growing body of research on the educational use of social software in three important ways: 1) we have highlighted the importance of focusing on the role of the educator. While the current literature nearly exclusively focuses on the characteristics and contributions of social software tools, we argue that the roles of the educator are an important element in the course of a social software initiative. 2) We have introduced role theory. By drawing on role theory, we have introduced a well-established framework from the sociology literature into the social software discourse which allows for a systematic conceptualisation of the educator role phenomenon. 3) We have developed a research agenda. Based on the insights from role theory we have identified several salient issues concerning the role of the educator in a social software environment and have developed an agenda for future investigations.

Although our application of role theory has highlighted a number of core issues and critical research questions, we have by no means exhausted the potential areas of research the body of theory presents us with. For example, further conceptualizations could integrate the impact of other contextual factors, such as the effects of: course format (part-time or full-time study, faceto-face or distance education), student characteristics (under-graduate or post-graduate, level of social software skills), or the combination of one or more social software tools that may be used in an initiative. Future research could also consider the impact an educator's individual personality has on the range of roles he or she performs. Another very important and promising research endeavor is the question of how these different educator roles influence the success and sustainability of the social software initiative. Such an investigation would provide insights into the significance of particular role behaviours and lead to the development of guidelines for educators. Role theory and its range of constructs and frameworks, as proposed in this paper, provide the appropriate basis for such investigations.

The educator is critical for the successful and sustainable use of social software for teaching and learning. Although the tools are readily available, it is the educator who purposefully introduces these tools into the context of higher and further education. The decision on adopting a particular

tool, the development of matching learning activities, and the moderation and facilitation within these tool environments are all roles and activities which directly contribute to the success of a social software initiative. It is very important for future research on social software to consider the importance of the educator as part of a social software initiative and to recognize the diversity of roles educators perform in this context.

\section{References}

Anderson, T. (2008). Teaching in an Online Learning Context. In T. Anderson \& F. Elloumi (Eds.), Theory and practice of online learning. Canada: Athabasca University.

Anderson, T., \& Elloumi, F. (2008). Theory and practice of online learning. Canada: Athabasca University. 
Berge, Z. L. (1995). The role of the online instructor/facilitator. Educational Technology, 35(1), 22-30.

Biddle, B. J. (1986). Recent Development in Role Theory. Annual Review of Sociology, 12, 6792.

Choy, S. O., \& Ng, K. C. (2007). Implementing wiki software for supplementing online learning. Australasian Journal of Educational Technology, 23(2), 209-226.

Davis, L. V. (1997). Role theory and social work treatment. In F. J. Turner (Ed.), Social Work Treatment: Interlocking Theoretical Approaches: The Free Press.

De Laat, M., Lally, V., Lipponen, L., \& Simons, R.-J. (2007). Online teaching in networked learning communities: A multi-method approach to studying the role of the teacher. Instructional Science, 35, 257-286.

Dennen, V. P. (2005). From message posting to learning dialogues: Factors affecting learner participation in asynchronous discussion. Distance Education, 26(1), 127-148.

Dickey, M. (2004). The impact of web-logs (blogs) on student perceptions of isolation and alienation in a web-based distance-learning environment. Open Learning: The Journal of Open and Distance Learning, 19(3), 279-291.

Dierdorff, E. C., \& Morgeson, F. P. (2007). Consensus in Work Role Requirements: The Influence of Discrete Occupational Context on Role Expectations. Journal of Applied Psychology 92(5), 1228-1241.

Du, H. S., \& Wagner, C. (2007). Learning with weblogs: Enhancing cognitive and social knowledge construction. IEEE Transactions on Professional Communication, 50(1), 116.

Franklin, T., \& Harmelen, M. v. (2007). Web 2.0 for Content for Learning and Teaching in Higher Education. Retrieved December 7, 2009, from http://franklinconsulting.co.uk/LinkedDocuments/Web2-Content-learning-and-teaching.pdf

Frydenberg, M. (2008). Wikis as a Tool for Collaborative Course Management. Journal of Online Learning and Teaching, 4(2), 169-181.

Greenhow, C., Robelia, B., \& Hughes, J. E. (2009). Learning, teaching, and scholarship in a digital age: Web 2.0 and classroom research, what path should we take now? Educational Researcher, 38(4), 246-259.

Heuer, B. P., \& King, K. P. (2004). Leading the Band: The Role of the Instructor in Online Learning for Educators. The Journal of Interactive Online Learning, 3(1), 1-11.

Hurlburt, S. (2008). Defining Tools for a New Learning Space: Writing and Reading Class Blogs. Journal of Online Learning and Teaching, 4(2), 182-189.

JISC. (2009). Higher Education in a Web 2.0 World Retrieved December 7, 2009, from http://www.jisc.ac.uk/media/documents/publications/heweb20rptv1.pdf

Jones, M. L. W., \& Gelb, D. (2009). Course co-creation vs course management In T. T. Kidd \& I. Chen (Eds.), Wired for Learning: An Educator's Guide to Web 2.0. Charlotte, NC: Information Age Publishing.

Kay, R. H. (2006). Developing a comprehensive metric for assessing discussion board effectiveness. British Journal of Educational Technology, 37(5), 761-783.

Kerawalla, L., Minocha, S., Kirkup, G., \& Conole, G. (2009). An empirically grounded framework to guide blogging in higher education. Journal of Computer Assisted Learning, 25(1), 31-42.

Kieslinger, B. (2009). How to Use Social Software in Higher Education. Retrieved December 5, 2009, from http://www.icamp.eu/wp-content/uploads/2009/01/icamp-handbook-web.pdf 
Lopata, H. Z. (1995). Role theory. In J. R. Blau, R. L. Coser \& N. Goodman (Eds.), Social roles and social institutions: Essays in honor of Rose Laub Coser. New Brunswick, NJ: Transaction Publishers.

Mantere, S. (2008). Role expectations and middle managers strategic agency. Journal of Management, 45(2), 294-316.

McGee, P., \& Diaz, V. (2007). Wikis and Podcasts and Blogs! Oh, My! What Is a Faculty Member Supposed to Do? EDUCAUSE Review, 42(5), 1-11.

McLoughlin, C., \& Lee, M. (2007). Social software and participatory learning: Pedagogical choices with technology affordances in the Web 2.0 era. Paper presented at the Ascilite

Minocha, S. (2009a). A case study-based investigation of students' experiences with social software tools. New Review of Hypermedia and Multimedia, 15(3), 245 -265.

Minocha, S. (2009b). A study on the effective use of social software by further and higher education in the UK to support student learning and engagement. Retrieved December 7, 2009, from http://www.jisc.ac.uk/media/documents/projects/effective-use-of-socialsoftware-in-education-finalreport.pdf

Parameswaran, M., \& Whinston, A. B. (2007). Social computing: An overview. Communications of the Association for Information Systems, 19, 762-780.

Roberson, T. J., \& Klotz, J. (2002). How Can Instructors and Administrators Fill the Missing Link in Online Instruction? Online Journal of Distance Learning Administration, 5(4).

Sieber, S. D. (1974). Toward a theory of role accumulation. American Sociological Review, 39(August), 567-578.

Taylor, P. G. (1999). Making Sense of Academic Life: Academics, Universities and Change. Florence, KY: Taylor and Francis Group.

Trentin, G. (2009). Using a wiki to evaluate individual contribution to a collaborative learning project. Journal of Computer Assisted Learning, 25(1), 43-55.

Wickham, M., \& Parker, M. (2007). Reconceptualising organisational role theory for contemporary organisational contexts. Journal of Managerial Psychology, 22(5), 440 464.

Winter, R., \& Sarros, J. (2002). The Academic Work Environment in Australian Universities: A motivating place to work? Higher Education Research \& Development, 21(3), 241-258. 
Table 1: Social software tools and their educational uses (adapted from Franklin \& Harmelen, 2007; McLoughlin \& Lee, 2007)

\begin{tabular}{l|c|} 
Description & Educational use/value \\
\hline $\begin{array}{l}\text { Discussion forum: Discussion forums allow users to post } \\
\text { and reply to individual messages, together creating a } \\
\text { threaded form of discourse. }\end{array}$ & $\bullet$ To discuss course or project related questions in small or large teams. \\
\hline $\begin{array}{l}\text { Blog: A web page presenting posts in reverse } \\
\text { chronological order (akin to diary entries) that allows a } \\
\text { single or a group of authors to write and publicly display } \\
\text { time-ordered notes or posts. }\end{array}$ & $\bullet \quad$ To comment on important posts made by other learners. \\
\hline $\begin{array}{l}\text { Wikis: A simple web page anyone can edit that enables a } \\
\text { group of individuals to create a collective resource (eg } \\
\text { wikipedia.org). Any edits can be easily reverted. }\end{array}$ & $\bullet \quad$ To build up a corpus of interrelated knowledge via interlinked posts and comments. \\
\hline $\begin{array}{l}\text { Social Bookmarking: A way to store and organize } \\
\text { bookmarks on the web, allowing people to build up } \\
\text { collections of classified and organised web resources, and } \\
\text { share both the bookmarks and tags with others (eg }\end{array}$ & $\bullet \quad$ To organize bookmatively edited material or for documenting group projects. \\
delicious.com). & $\bullet \quad$ To establish a useful collection of resources in a project team. \\
\hline
\end{tabular}




\begin{tabular}{|l|cl|}
\hline $\begin{array}{l}\text { Video \& Podcasting: Video \& Podcasting services store } \\
\text { user-contributed media, and allow users to search for and } \\
\text { display content (eg youtube.com, podcastalley.com) }\end{array}$ & $\begin{array}{l}\text { To produce reflective or creative assignments and interviews. } \\
\text { To provide introductory material before lectures, or to record lectures for later review. }\end{array}$ \\
\hline $\begin{array}{l}\text { Image sharing: Web-based image sharing tools allow } \\
\text { users to upload, tag, share, annotate, and discuss images } \\
\text { and photos (eg flickr.com). }\end{array}$ & $\begin{array}{l}\text { To share photos within a class, school, department, faculty, college, or university. } \\
\end{array}$ & $\begin{array}{l}\text { To build communities in distance education }- \text { i.e. students share photos of themselves. } \\
\text { audience and to collect feedback. }\end{array}$ \\
\hline $\begin{array}{l}\text { Microblogging: Microblogging allows the posting of short } \\
\text { notices which other users of the service can subscribe to } \\
\text { (eg twitter.com). }\end{array}$ & $\bullet \quad \begin{array}{l}\text { To form social networks with other learners. } \\
\text { Tocial Networking: Social networking sites are integrated } \\
\text { suites of tools allowing users to create profiles and form } \\
\text { connections with other people. Images, status updates, } \\
\text { event invitations, emails, and videos can then be shared } \\
\text { with others (eg facebook.com). }\end{array}$ & $\bullet \quad$ To receive class updates and reminders. \\
\hline
\end{tabular}




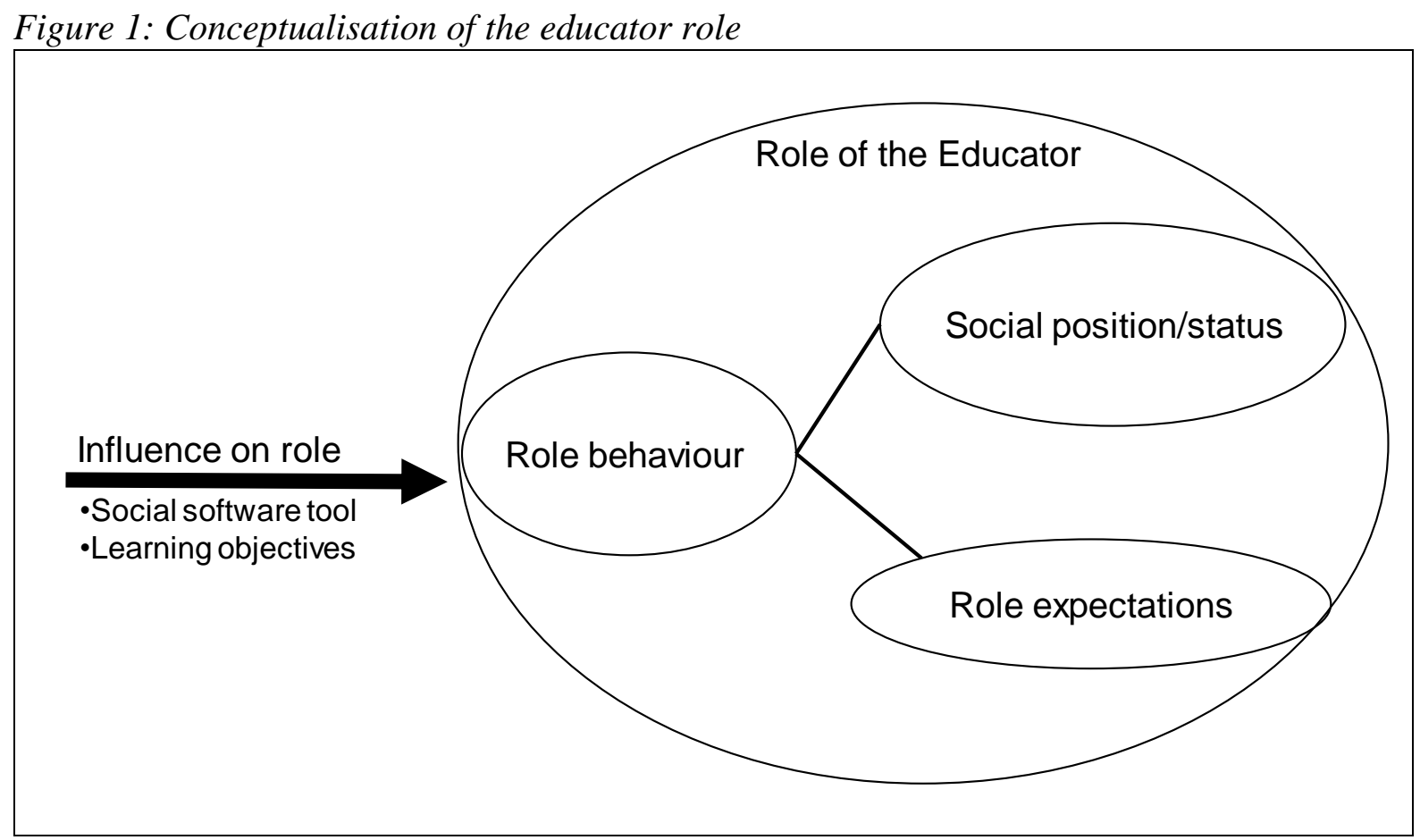

